\title{
LEVANTAMENTO DA QUALIDADE DA BEBIDA DO CAFÉ E AVALIAÇÃO DO ESTADO NUTRICIONAL DOS CAFEEIROS DO ALTO JEQUITINHONHA, MINAS GERAIS, ATRAVÉS DO DRIS ${ }^{1}$
}

\author{
Coffee beverage quality survey and evaluation of the nutritional state of coffee treee \\ in the High Jequitinhonha, state of Minas Gerais, Brazil, using DRIS ${ }^{1}$
}

\author{
Múcio Mágno de Melo Farnezi², Enilson de Barros Silva ${ }^{3}$, \\ Paulo Tácito Gontijo Guimarães ${ }^{4}$, Nísia Andrade Villela Dessimoni Pinto ${ }^{5}$
}

\begin{abstract}
RESUMO
A região do Alto Jequitinhonha tem se apresentado como expressivo parque cafeeiro do estado de Minas Gerais. No entanto, têm-se pouca informação sobre a influência do estado nutricional do cafeeiro sobre a qualidade da bebida juntamente com a produção. Objetivou-se, neste trabalho, foi realizar o levantamento da qualidade da bebida do café (Coffea arabica L.) e avaliar o estado nutricional dos cafeeiros do Alto Jequitinhonha, através do DRIS. Obtiveram-se as produções, as atividades enzimáticas da polifenoloxidase dos grãos de café e os teores foliares dos nutrientes em duas safras (2005 e 2006), para o cálculo do DRIS, com vistas a efetuar o diagnóstico nutricional do cafeeiro. A região do Alto Jequitinhonha apresentou aptidão para produzir cafés de melhor qualidade (bebida "mole", "apenas mole" e "estritamente mole"), e o melhor estado nutricional das lavouras cafeeiras proporcionou produtividade de grãos de 65,0 sacas ha-1 e qualidade de bebida "mole" e "apenas mole".
\end{abstract}

Termos para indexação: Café, Coffea arabica, diagnose foliar, polifenoloxidase, índice de coloração, açúcares totais.

\section{ABSTRACT}

Coffee crops in the region of the High Jequitinhonha, State of Minas Gerais, Brazil, has become more expressive. However, there is still little information on the influence of the nutritional state of the coffee tree on the beverage quality and the yield. The objective of this work was to carry out a survey of the quality of the coffee beverage and assess the nutritional status of the High Jequitinhonha, using DRIS. Yield, polyphenyloxidase enzyme activity of the grains coffee and leaf nutrient contents were observed in two crops (2005 and 2006) for the calculation of DRIS for a diagnosis of the nutritional state of the coffee. The region of the High Jequitinhonha can produce higher quality coffee ( "soft", "barely soft" and "strictly soft" beverages), and the best nutritional status of coffee plantations produced 65.0 sacks ha ${ }^{-1}$ and beverage qualities "soft" and "barely soft."

Index terms: Coffee, Coffea arabica, foliar diagnosis, poliphenyloxidase, coloration index, total sugars.

(Recebido em 29 de agosto de 2008 e aprovado em 6 de maio de 2009)

\section{INTRODUÇÃO}

O Alto Jequitinhonha apresenta-se como uma região emergente no cenário mineiro, sendo a sua cafeicultura atividade de expressão, exercendo importante papel sócioeconômico, contribuindo na geração de empregos, na renda e no dinamismo da economia regional. O Vale do Jequitinhonha, juntamente com as regiões produtoras da Zona da Mata, Mucuri, Rio Doce, Central e Norte contribui com 28,9\% da produção de café de Minas Gerais (Companhia Nacional de Abastecimento - CONAB, 2008). Dessa forma, pesquisas devem ser realizadas para identificar quais os nutrientes são mais limitantes para a produção do cafeeiro, enfatizando a influência da nutrição mineral na qualidade dos grãos de café.
Os grãos de café têm sido avaliados quimicamente e a bebida sensorialmente o que depende muito das condições do provador de bebida, durante a avaliação (Chagas et al., 1996; Mazzafera et al., 2002; Bataglia, 2007). Existe, no entanto, uma relação correspondente entre ambos os modos de avaliação (Carvalho et al., 1994).

A polifenoloxidase é uma enzima cúprica que, de acordo com vários autores, se mostra diretamente relacionada com a qualidade da bebida do café (Carvalho et al., 1994; Chagas et al., 1996; Mazzafera et al., 2002; Silva et al., 2009).

Segundo Carvalho et al. (1994), cafés de melhor qualidade de bebida possuem elevada atividade enzimática da polifenoloxidase e elevado índice de coloração.

${ }^{1}$ Parte da Dissertação de Mestrado do primeiro autor. Programa de Pós-Graduação em Produção Vegetal da Universidade Federal dos Vales do Jequitinhonha e Mucuri/UFVJM - Trabalho financiado pela FAPEMIG

2Universidade Federal dos Vales do Jequitinhonha e Mucuri/UFVJM - Rua da Glória 187 - 39100-000 - Diamantina, MG - muciomagno@yahoo.com.br ${ }^{3}$ Universidade Federal dos Vales do Jequitinhonha e Mucuri/UFVJM - Departamento de Agronomia - Diamantina, MG

${ }^{4}$ Empresa de Pesquisa Agropecuária de Minas Gerais/EPAMIG - Lavras, MG

5Universidade Federal dos Vales do Jequitinhonha e Mucuri/UFVJM - Departamento de Nutrição - Diamantina, MG 
Verificou-se que as variações da atividade enzimática da polifenoloxidase, permitem separar as classes de bebida, considerando para o café "riado e rio" atividades inferiores a 55,99 $\mathrm{U} \mathrm{g}^{-1}$ de amostra; nos cafés de bebida "dura" atividades entre 55,99 e 62,98 $\mathrm{U} \mathrm{g}^{-1}$ de amostra; nos cafés de bebida "mole" atividades entre 62,98 e 67,65 $\mathrm{U} \mathrm{g}^{-1} \mathrm{de}$ amostra e nos cafés de bebida "estritamente mole" atividades superiores a $67,65 \mathrm{U} \mathrm{g}^{-1}$ de amostra, constatando assim um aumento significativo na atividade da polifenoloxidase à medida que o café se apresenta com melhor qualidade. Quanto ao índice de coloração, cafés de melhor qualidade apresentam maior índice de coloração; cafés de piores bebidas (riado e rio) apresentam índices de coloração inferiores a $0,70 \mathrm{~nm}$.

Arcila-Pulgarin \& Valência-Aristizabal (1975), estudando acidez em cafés de diferentes qualidades detectaram maior acidez em café de pior qualidade. Variações na acidez dos grãos foram investigadas por Carvalho et al. (1994) e Abreu et al. (1996), que observaram haver uma relação inversa entre os teores de acidez e a qualidade dos grãos.

Segundo Amorim et al. (1976), os açúcares não parecem afetar a qualidade do café, de um modo geral. No entanto, deve-se ressaltar que os açúcares participam de importantes reações químicas que ocorrem durante a torração, como reação de Maillard e/ou caramelização, que serão responsáveis pela formação da cor, sabor e aroma peculiares da bebida (Chagas et al., 1996).

A avaliação do estado nutricional de plantas é uma importante ferramenta para a adequada utilização de fertilizantes e tem como principal objetivo identificar os nutrientes que limitam o crescimento, desenvolvimento, produção (Silva et al., 2003) e qualidade do produto.

A análise química foliar vem sendo usada para detectar respostas de cafeeiros aos vários tipos de manejo, possibilitando interpretar, de maneira mais eficiente, as relações entre nutrientes na planta. Segundo Corrêa et al. (2001), análise química foliar é baseada em métodos padronizados de amostragem, padrões de referência de teores foliares e interpretação de resultados, e é o critério mais eficiente na avaliação do estado nutricional de plantas. Sua maior vantagem está no fato de se considerar a própria planta como extrator dos nutrientes no solo e permitir uma avaliação direta de seu estado nutricional e, desse modo, avaliar as concentrações e as relações entre nutrientes, constituindo, assim, uma forma indireta de avaliação da fertilidade do solo (Malavolta et al., 1997).

Dentre os métodos utilizados para interpretação dos resultados das análises químicas foliares, há o sistema integrado de diagnose e recomendação (DRIS), entre outros (Cantatutti et al., 2007). O DRIS baseia-se no cálculo de um índice para cada nutriente, comparando-se as relações entre um nutriente e cada um dos demais nutrientes na amostra sob diagnose com as relações envolvendo esse mesmo nutriente em uma população de referência (Corrêa et al., 2001; Cantatutti et al., 2007). Cada relação entre nutrientes na população de alta produtividade constitui uma norma DRIS e tem sua respectiva média e coeficiente de variação. O índice DRIS, possibilita definir o grau de desvio dos nutrientes da amostra e sua localização em relação ao estado nutricional, se adequado, em deficiência ou em excesso (Reis Júnior \& Monnerat, 2003). Quanto mais próximo de zero estiver o índice do nutriente, mais próximo do equilíbrio nutricional o nutriente se encontra; índice positivo indica que o nutriente está em excesso e índice negativo, deficiente (Beaufils, 1971). As normas DRIS são úteis para estudar os desequilíbrios nutricionais e aumentar a produtividade da cultura, quando se realiza a correção do nutriente indicado no diagnóstico (Reis Júnior \& Monnerat, 2003).

Objetivou-se, neste trabalho, realizar o levantamento da qualidade da bebida do café (Coffea arabica L.) e avaliar o estado nutricional dos cafeeiros do Alto Jequitinhonha, através do DRIS.

\section{MATERIAL E MÉTODOS}

Foram selecionadas 52 lavouras cafeeiras (Coffea arabica L.) representativas da região do Alto Jequitinhonha do estado de Minas Gerais, nos municípios de Capelinha, Diamantina, Presidente Kubitschek, Felício do Santos, São Gonçalo do Rio Preto, Angelândia, Setubinha e Água Boa. Em cada lavoura foi demarcado um talhão de um hectare e selecionadas 25 plantas úteis das quais foram coletados os dados de produção, amostras de folhas para determinação de nutrientes e uma amostra de $3 \mathrm{~kg}$ de café em coco, na época da colheita. O café foi colhido no pano e seco em terreiro cimentado em duas safras (2005 e 2006). As amostras de café em coco foram beneficiadas no Laboratório de Bromatologia da UFVJM no município de Diamantina, MG. Esse procedimento foi adotado para uniformizar as amostras para o levantamento da qualidade da bebida do café.

As amostragens para as determinações dos teores foliares dos nutrientes foram feitas coletando-se os $3^{0}$ e $4^{0}$ pares de folhas a partir da ponta do ramo lateral e inserido na altura média da planta e ao redor da mesma, no mês de dezembro (fruto em estádio de "chumbinho"), com um total de 250 folhas por talhão. Após a coleta, as amostras de folhas foram analisadas quimicamente para determinação dos teores de $\mathrm{N}, \mathrm{P}, \mathrm{K}, \mathrm{Ca}, \mathrm{Mg}, \mathrm{S}, \mathrm{B}, \mathrm{Cu}, \mathrm{Fe}, \mathrm{Mn}$ e $\mathrm{Zn}$, 
conforme metodologia descrita por Malavolta et al. (1997). Os dados de produção de frutos em coco, das 25 plantas selecionadas foram convertidos em produtividade de sacas de $60 \mathrm{~kg}$ de café beneficiado por hectare.

A atividade enzimática da polifenoloxidase (PFO), referente a cada cafezal amostrado foi determinada em amostras de grãos de café beneficiados, moídos em moinho tipo Croton Mod.TE-580, com peneira de 30 mesh. O método de extração da enzima consistiu na extração descrita por Draetta \& Lima (1976). A atividade enzimática foi determinada pelo método descrito por Ponting \& Joslyng (1948), utilizando-se o extrato da amostra sem DOPA (3,4 dihidroxifenil-alanina), como branco, expressa em $\mathrm{U} \mathrm{g}^{-1} \mathrm{de}$ grãos beneficiados (U é a unidade de atividade enzimática equivalente a 0,001 da densidade ótica por minuto).

O índice de coloração (IC) foi determinado pelo método descrito por Singleton (1966). A acidez titulável total (ATT) foi determinada por titulação com $\mathrm{NaOH} 0,1$ mol L ${ }^{-1}$ de acordo com técnica descrita pela Association of Official Analytical Chemists - AOAC (1990), e expressa em $\mathrm{mL}$ de $\mathrm{NaOH}$ por $100 \mathrm{~g}^{-1}$ de amostra. Os açúcares totais (AT) foram extraídos pelo método de Lane-Enyon, citado pela AOAC (1990).

Para verificar o estado nutricional do cafeeiro do Alto Jequitinhonha, obtiveram-se os índices DRIS, a partir dos teores totais dos nutrientes das folhas, em um total de 104 dados de amostras. Os índices DRIS para cada nutriente foram calculados por meio da fórmula:

$\mathrm{IN}=[\mathrm{Z}(\mathrm{A} / \mathrm{B})+\mathrm{Z}(\mathrm{A} / \mathrm{C})+\ldots+\mathrm{Z}(\mathrm{A} / \mathrm{N})-\mathrm{Z}(\mathrm{B} / \mathrm{A})-\mathrm{Z}(\mathrm{C} / \mathrm{A})-$ $\ldots-\mathrm{Z}(\mathrm{N} / \mathrm{A})] /[(\mathrm{n}+\mathrm{m})]$

Para o cálculo da função $\mathrm{Z}(\mathrm{A} / \mathrm{B})$ foi utilizada a fórmula recomendada por Jones (1981), em que: Z (A/B) = [(A/B) - (a/b)] x K/s, em que: Z(A/B) = função da relação entre os nutrientes $\mathrm{A}$ e $\mathrm{B}$ da $\operatorname{amostra} ;(\mathrm{A} / \mathrm{B})=$ valor da relação entre os nutrientes $A$ e $B$ na amostra; $a / b=$ valor da norma média para as relações $A / B$, na população de referência; $\mathrm{K}=$ valor constante e arbitrário (valor $=10)$; $\mathrm{s}=$ desvio padrão dos valores da relação $\mathrm{A} / \mathrm{B}$, da população de referência; $\mathrm{n}=$ número de funções em que o nutriente $\mathrm{A}$ aparece no denominador; $\mathrm{m}=$ número de funções e o nutriente A aparece no numerador.

As lavouras amostradas com produtividade igual e superior a 30 sacas por hectare e qualidade da bebida acima da classificação "dura" (PFO > 62,99 U g ${ }^{-1}$ de amostra) (grupo A) foram consideradas como lavouras-padrão (grupo de referência) para o cálculo da média, desvio padrão e coeficiente de variação. $\mathrm{O}$ grupo $\mathrm{B}$, foi constituído de lavouras com produtividade abaixo de 30 sacas ha $^{-1}$ com qualidade da bebida inferior, igual e superior à classificação "dura" e com alta produtividade com qualidade igual e inferior à bebida "dura" (PFO $£$ 62,99 $\mathrm{U} \mathrm{g}^{-1}$ de amostra).

Para o levantamento da qualidade da bebida foram separadas as classes de bebida através da atividade da polifenoloxidase, segundo Carvalho et al. (1994) e foi realizada uma análise estatística e estudo de média (teste de Tukey, a 5\%) após a separação das classes de bebida para as variáveis PFO, ATT, IC e AT.

Obtidos os índices DRIS dos dois anos de avaliação (2005 e 2006), calculou-se o índice de balanço nutricional médio $\left(\mathrm{IBN}_{\mathrm{m}}\right)$ pelo somatório dos valores absolutos dos índices DRIS, dividindo pelo número (N) de nutrientes avaliados, conforme a equação: $\mathrm{IBN}=\left(\left|\mathrm{IN}_{\mathrm{A}}\right|+\left|\mathrm{IN}_{\mathrm{B}}\right|+\ldots+\left|\mathrm{IN}_{\mathrm{N}}\right| / \mathrm{N}\right)$, para verificar o balanço nutricional global das lavouras.

\section{RESULTADOS E DISCUSSÃO}

Verifica-se que, na classificação da qualidade da bebida do café, a maior porcentagem das amostras avaliadas está na classe de bebida "dura" (Tabela 1). Podese destacar que a soma das classes de bebida "apenas mole" e "mole" e "estritamente mole" corresponde a $37 \%$ dos cafés avaliados. A partir desses resultados de classificação da qualidade da bebida do café, na região do Alto Jequitinhonha pode se inferir que é possível produzir cafés de qualidade acima de bebida "dura", o que pode estar associado às condições climáticas favoráveis da região. No entanto, existe a necessidade de padronização dos cafés dessa região.

A maior ocorrência de bebida "dura" é comum também quando se utiliza a classificação feita por provadores, pelo teste sensorial conhecido como "prova de xícara" (Chagas et al., 1996). A atividade enzimática da polifenoloxidase dos grãos apresenta relação positiva com a qualidade da bebida do café, conforme verificado por Amorim et al. (1976), Carvalho et al. (1994), Leite \& Carvalho (1994), Chagas et al. (1996), Martins et al. (2005), Santos et al. (2009) e Silva et al. (2009).

Não houve diferenças significativas quanto à acidez titulável total (ATT) nos padrões de bebida do café (Tabela 1). No entanto, a ATT dos grãos de café apresenta uma relação inversa com a qualidade da bebida do café, segundo Carvalho et al. (1994), pois cafés de melhor qualidade possuem maior atividade enzimática da polifenoloxidase e menor acidez titulável total. Verifica-se uma tendência de aumento da ATT com a redução da PFO 
dos grãos de café (Tabela 1). Essa maior acidez pode estar associada a um maior nível de fermentação microbiana nos frutos das lavouras avaliadas. Segundo Coelho et al. (2002), a infecção de microrganismos favorece fermentação produzindo álcool, que é desdobrado em ácidos acético, láctico, propiônico e butírico os quais proporcionam acentuados prejuízos à qualidade da bebida do café.

O índice de coloração (IC) de grãos de café tem uma relação direta com a PFO (Tabela 1). Os grãos de café com maior atividade da polifenoloxidase, ou seja, melhor qualidade de bebida, também apresentaram tendência de maior IC conforme Carvalho et al. (1994), apesar de não existirem diferenças significativas entre as classes de bebida do café (Tabela 1). Cafés de melhor qualidade possuem maior PFO e IC, conforme pesquisas desenvolvidas por, Carvalho et al. (1994), Leite \& Carvalho (1994), Chagas et al. (1996), Silva et al. (2002) e Silva et al. (2009).

Observam-se, também, relações diretas entre a PFO, IC e açúcares totais (AT) (Tabela 1). No presente trabalho, os teores AT determinados nos grãos colhidos na região do Alto Jequitinhonha estão em torno de $8,0 \%$; porcentagem próxima das encontradas por Chagas et al. (1996) e Silva et al. (2002), para cafés de melhor qualidade de bebida.

Os açúcares podem contribuir para o sabor e aroma do café, conforme cita Chagas et al. (1996), mas esses atributos ainda não participam das classificações oficiais de qualidade de bebida adotada pelo mercado. Os cafés de melhor qualidade possuem maiores teores de açúcares totais, fato verificado por Chagas et al. (1996) e Silva et al. (2002).

A partir da observação da Tabela 2, verifica-se maior frequência de lavouras (36\%) de baixa produtividade, com qualidade de bebida inferior ("riada e rio" e "dura"); ao passo que, em lavouras com alta produtividade observase uma tendência de maiores porcentagens de lavouras
(25\%) com cafés de melhor qualidade ("bebida mole e apenas mole" e "estritamente mole"), segundo classificação de Carvalho et al. (1994), do que lavouras com baixa produtividade $(12 \%)$.

Os índices DRIS podem assumir valores negativos, quando ocorre deficiência do elemento considerado em relação aos demais. Valores positivos indicam excesso e, quanto mais próximos de zero estiverem, mais próxima estará a planta do equilíbrio nutricional para o elemento em estudo (Beaufils, 1971). Ainda, o DRIS permite a determinação da sequência de limitação nutricional (Partelli et al., 2006), permitindo a classificação dos elementos em ordem de importância para produção ; e nesse caso, comprova-se a qualidade da bebida do café, pois os índices DRIS foram obtidos de uma norma com população de referência de alta produtividade e qualidade de bebida acima de "dura", conforme discutido anteriormente; fornecendo, ao mesmo tempo, uma indicação da intensidade de exigência de determinado elemento. A partir dessa inferência e pela observação da Tabela 2, de forma geral pôde-se verificar que o $\mathrm{Mn}, \mathrm{Fe}, \mathrm{Ca}, \mathrm{P}, \mathrm{S}$ e B foram os nutrientes mais limitantes por deficiência (índice negativo), nessa ordem, enquanto, os nutrientes $\mathrm{Zn}, \mathrm{Cu}, \mathrm{N}, \mathrm{K}$ e $\mathrm{Mg}$ foram os que mais limitaram por excesso (índice positivo), na produtividade de grãos e qualidade da bebida do café.

Através da observação dos índices DRIS (Tabela 2); pôde-se inferir com maior precisão que, na medida em que aumentou a produtividade e qualidade da bebida do café, mais próximos de zero ficaram os índices, ou seja, as lavouras que apresentaram mais produtivas e com melhor qualidade da bebida do café estão mais equilibradas nutricionalmente. Portanto, esse resultado confirma que a nutrição equilibrada leva à maior produtividade, podendo também, atingir a melhor qualidade.

Tabela 1 - Classificação da bebida, frequência de ocorrência, PFO, ATT, IC e AT dos grãos de café da região do Alto Jequitinhonha, MG.

\begin{tabular}{lccccc}
\hline Classificação da bebida & Frequência de ocorrência (\%) & PFO $^{(1)}$ & ATT & IC & AT \\
\hline Riada e Rio & 19 & $52,95 \mathrm{~d}$ & $208 \mathrm{a}$ & $0,929 \mathrm{a}$ & $6,8 \mathrm{~d}$ \\
Dura & 44 & $59,84 \mathrm{c}$ & $194 \mathrm{a}$ & $0,978 \mathrm{a}$ & $7,6 \mathrm{c}$ \\
Apenas Mole e Mole & 16 & $65,08 \mathrm{~b}$ & $187 \mathrm{a}$ & $1,058 \mathrm{a}$ & $8,2 \mathrm{~b}$ \\
Estritamente Mole & 21 & $69,00 \mathrm{a}$ & $185 \mathrm{a}$ & $1,083 \mathrm{a}$ & $8,7 \mathrm{a}$ \\
\hline Média & & 61,72 & 194 & 1,012 & 7,8 \\
\hline CV $(\%)$ & & 9,1 & 17,9 & 21,3 & 8,8 \\
\hline
\end{tabular}

Médias seguidas pela mesma letra na coluna não diferem entre si pelo teste de Tukey, a 5\%. ${ }^{(1)}$ PFO - atividade de polifenoloxidase ( $\mathrm{U} \mathrm{g}^{-1}$ de amostra), ATT - acidez titulável total (mL NaOH $\left.100 \mathrm{~g}^{-1}\right)$, IC - índice de coloração (D.O. $\left.435 \mathrm{~nm}\right)$ e AT - açúcares totais $(\%)$. 


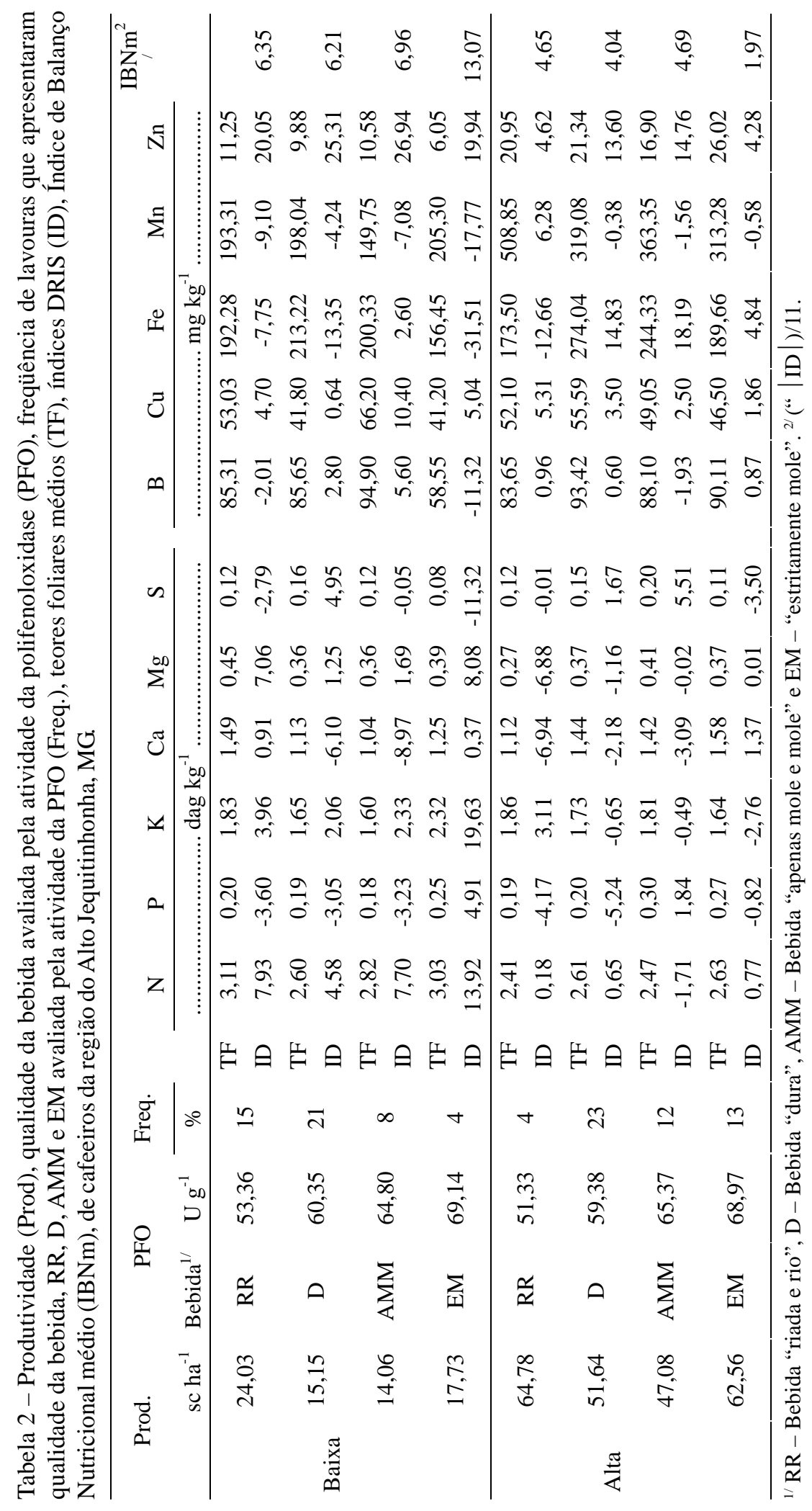


A soma dos índices DRIS, em módulo, dividido pelo número de nutrientes fornece o Índice de Balanço Nutricional médio $\left(\mathrm{IBN}_{\mathrm{m}}\right)$, que permite comparar o equilíbrio nutricional das lavouras entre si (Silva et al., 2003). A relação entre produção de grãos e a qualidade da bebida avaliada pela atividade da polifenoloxidase (PFO), com os valores de IBNm é apresentada na Figura 1, confeccionada com os dados da Tabela 2.

$\mathrm{IBNm}=135,3+0,9851 * *$ Prod $-0,004968 * * \operatorname{Prod}^{2}-$ $4,95914 *$ PFO + 0,0457307** $\mathrm{PFO}^{2}-0,0118499 * * \operatorname{Prod}^{*} \mathrm{PFO}$ $\mathrm{R}^{2}=0,95$

Pelos resultados observa-se que, quando o cafeeiro está com desbalanço nutricional (desequilíbrio nutricional), esse proporciona uma baixa produtividade, podendo, no entanto, a bebida ser de boa qualidade (bebida "mole, apenas mole" e "estritamente mole"). Quando o cafeeiro está com melhor balanço nutricional (equilíbrio nutricional) ocorre uma elevada produtividade de grãos, mas pode ocorrer tanto a bebida de baixa qualidade (bebida "rio" e "riada"), como também bebida de boa qualidade (bebida acima de "dura").

Pela equação da superfície de resposta, comparando-se os coeficientes lineares, verifica-se que o balanço nutricional das lavouras cafeeiras tem uma maior relação com a produtividade do que a qualidade da bebida do café avaliada pela PFO (Figura 1). Essa tendência é justificada pela maior facilidade de se avaliar a produção das culturas, ao contrário da qualidade dos produtos agrícolas, que não é facilmente definida ou medida (Silva et al., 2003), somente com uma simples variável; apesar de a PFO ter uma boa correlação com a qualidade da bebida do café avaliada pela "prova de xícara" (Amorim et al., 1976; Carvalho et al., 1994; Chagas et al., 1996; Martins et al., 2005; Santos et al., 2009; Silva et al., 2009). Silva et al. (2003), constataram que o IBN de lavouras cafeeiras apresentou comportamento bastante próximo do modelo teórico com relação inversa à produção do cafeeiro com ajuste de coeficiente de correlação linear simples $(r=0,72)$, e observaram ainda que a mesma tendência ocorreu entre o IBN e a qualidade da bebida, porém com coeficiente de correlação linear $(r=0,45)$ inferior ao encontrado para produção. Além disso, verifica-se que existe uma interação da produtividade e qualidade da bebida com o estado nutricional do cafeeiro (Equação de superfície de resposta), de forma que, com aumento da produtividade e qualidade da bebida, ocorre uma redução do IBN.

A partir da derivação da equação da Figura 1, verifica-se que, o máximo de desequilíbrio nutricional $\left(\mathrm{IBN}_{\mathrm{m}}\right.$ estimado $=6,0$ ) das lavouras cafeeiras, corresponde à produtividade de 29,8 sacas ha-1 e PFO de 58,09 $\mathrm{U} \mathrm{g}^{-1}$ de amostra grãos de café classificado como bebida "dura", conforme Carvalho et al. (1994). Para o máximo equilíbrio nutricional das lavouras cafeeiras $\left(\mathrm{IBN}_{\mathrm{m}}=0\right)$, a produtividade atingida é de 65,0 sacas ha $^{-1}$ e PFO de 67,57 $\mathrm{U} \mathrm{g}^{-1}$ de amostra de grãos de café classificado como bebida "mole" e "apenas mole", de acordo com a tabela proposta
A

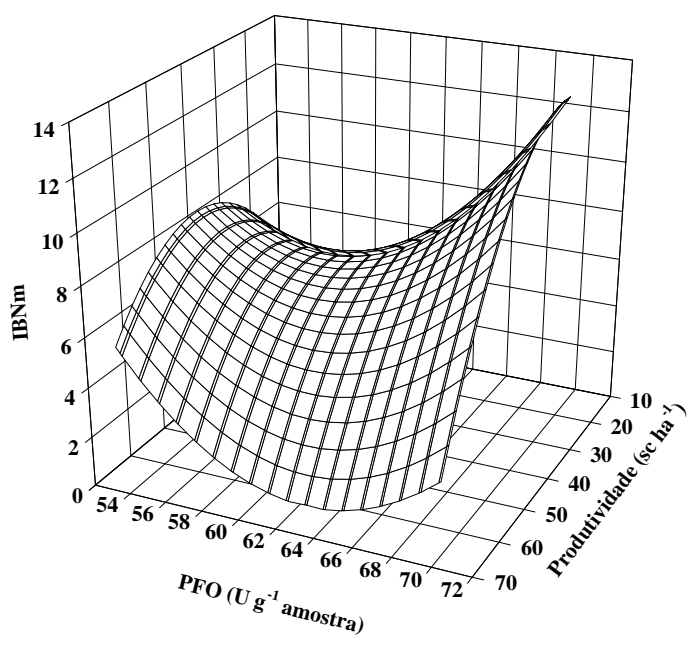

B

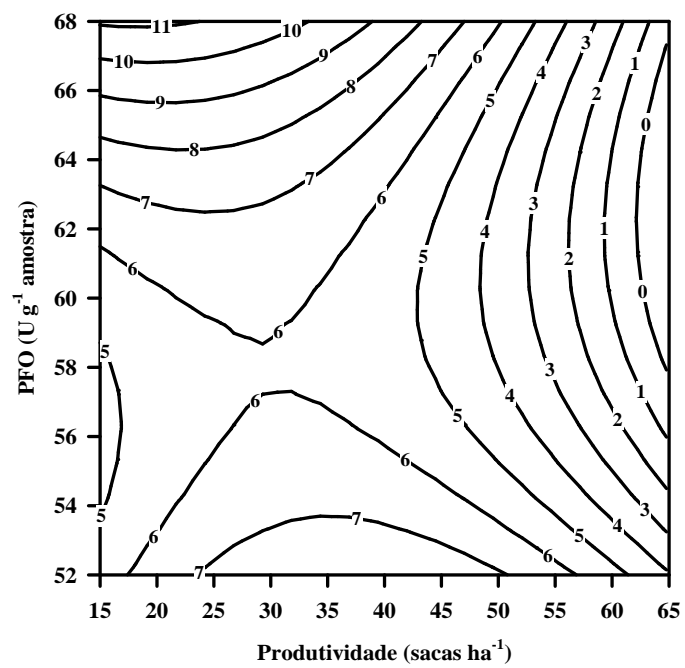

Figura 1 - Superfície de resposta entre índice de balanço nutricional médio (IBNm), produtividade e atividade enzimática da polifenoloxidase (PFO) de grãos (A) e isotermas das variáveis (B), para cafeeiros da região do Alto Jequitinhonha, MG.(** significativo, a $1 \%$ pelo teste de $\mathrm{t})$.

Ciênc. agrotec., Lavras, v. 34, n. 5, p. 1191-1198, set./out., 2010 
por Carvalho et al. (1994). Com o melhor estado nutricional das lavouras cafeeiras, a partir do modelo, obteve-se uma produtividade $314 \%$ maior que a média das regiões Zona da Mata, Jequitinhonha, Mucuri, Rio Doce, Central e Norte, que foi de 15,7 sacas ha-1 na safra 2007 (CONAB, 2008), e também com qualidade da bebida superior a "dura", sendo essa bebida o limite da faixa proposta por Carvalho et al. (1994), de não aceitação e aceitação da qualidade da bebida, no mercado de comércio de café. No contrário $\left(\mathrm{IBN}_{\mathrm{m}}=\right.$ 6,0 ), verifica-se produtividade $89,8 \%$ maior que a média das regiões, porém com qualidade de bebida inferior.

Portanto, ideal seria um bom balanço nutricional do cafeeiro que proporcionasse uma elevada produtividade de grãos com melhor qualidade da bebida do café. Entretanto, de acordo com Bataglia (2007), integrar as áreas de nutrição e de qualidade dos produtos agrícolas é difícil, pois vários fatores podem influenciar a qualidade, além do "problema" da especificidade de cada pesquisador na sua área de trabalho.

\section{CONCLUSÕES}

A maior parte das lavouras avaliadas da região do Alto Jequitinhonha apresentou qualidade da bebida classificada como "dura". No entanto, a região apresenta aptidão para produzir cafés de melhor qualidade (bebida "mole", "apenas mole" e "estritamente mole"). O melhor equilíbrio do estado nutricional das lavouras cafeeiras proporcionou produtividade de 65,0 sacas ha-1 de café beneficiado e qualidade de bebida "mole" e "apenas mole". A manutenção do equilíbrio do estado nutricional da lavoura proporciona elevada produtividade e qualidade da bebida do café.

\section{AGRADECIMENTOS}

À Universidade Federal dos Vales do Jequitinhonha e Mucuri (UFVJM), à Fundação de Amparo à Pesquisa do Estado de Minas Gerais (FAPEMIG), à Coordenação de Aperfeiçoamento de Pessoal de Nível Superior (CAPES) e à Prefeitura Municipal de Presidente Kubitschek, pelo apoio e cooperação.

\section{REFERÊNCIAS BIBLIOGRÁFICAS}

ABREU, C.M.A.; CARVALHO, V.D. de; BOTREL, N. Efeito de níveis de adição de defeito verde na composição química de cafés classificados com bebida estritamente mole. Pesquisa Agropecuária Brasileira, Brasília, v.31, n.6, p.456-561, 1996.

AMORIM, H.V.; LEGENDRE, M.G.; AMORIM, V.L.; ANGELO, A.J.S.; ORY, R.L. Chemistry of Brazilian green coffee and the quality of the beverage: VII., total carbanyls, activity of polyphenol oxidase, and hydroperoxides. Turrialba, San José, v.26, n.2, p.193-195, 1976.

\section{ARCILA-PULGARIN, J.; VALÊNCIA-ARISTIZÁBAL, G} Relacion entre la actividade de la polifenol oxidasa (P.F.O.) y las pruebas de catacion como medidas de la calidad de la bebida del cafe. Cenicafé, Caldas, v.26, n.2, p.55-71, abr./jun. 1975.

\section{ASSOCIATION OF OFFICIAL ANALYTICAL CHEMISTRY. Official methods of analysis of the Association of Official Analytical Chemists. 15.ed. Washington, 1990. 684p.}

BATAGLIA, O.C. Efeito da nutrição mineral sobre a qualidade dos grãos e da bebida do café. In: SALVA, T. de J.G. et al. (Eds.). Cafés de qualidade: aspectos tecnológicos, científicos e comerciais. Campinas: Instituto Agronômico, 2007. p.51-71.

BEAUFILS, E.R. Physiological diagnosis: a guide for improving maize production basead on principles developed for rubber trees. Fertilizer Society of South Africa Journal, Pietermaritzburg, v.1, n.1, p.1-30, 1971.

CARVALHO, V.D.; CHAGAS, S.J. de R.; CHALFOUN, S.M.; BOTREL, N.; JUSTE JUNIOR, E.S.G. Relação entre a composição físico-química e química do grão beneficiado e a qualidade de bebida do café. Pesquisa Agropecuária Brasileira, Brasília, v.29, n.3, p.449-454, mar. 1994

CHAGAS, S.J. de R.; CARVALHO, V.D.; COSTA, L. Caracterização química e qualitativa de cafés de alguns municípios de três regiões produtoras de Minas Gerais. Pesquisa Agropecuária Brasileira, Brasília, v.31, n.8, p.555-561, ago. 1996.

COELHO, K.F.; PEREIA, R.G.F.A. Influência de grãos defeituosos em algumas características químicas do café cru e torrado. Ciência e Agrotecnologia, Lavras, v.26, n.2, p.375-384, mar./abr. 2002.

\section{COMPANHIA NACIONAL DE ABASTECIMENTO.} Acompanhamento da safra brasileira de café, safra 2008, primeira estimativa, janeiro/2008. Disponível em: $\langle$ http://Www.google.com.bry. Acesso em: 18 abr. 2008. 
CORREAA, J.B.; REIS JÚNIOR, R. dos A.; CARVALHO, J.G.; GUIMÃRAES, P.T.G. Avaliação da fertilidade do solo e do estado nutricional de cafeeiros do Sul de Minas Gerais. Ciência e Agrotecnologia, Lavras, v.25, n.6, p.1279-1286, nov./dez. 2001.

DRAETTA, I.S.; LIMA, D.C. Isolamento e caracterização das polifenoloxidases do café. Coletânea do Instituto de Tecnologia de Alimentos, Campinas, v.17, p.3-28, 1976.

JONES, C.A. Proposed modifications of the diagnosis and recommendation integrated system (DRIS) for interpreting plant analyses. Communications in Soil Science and Plant Analysis, New York, v.12, n.8, p.785794, 1981.

LEITE, I.P.; CARVALHO, V.D. Influência do local de cultivo e do tipo de colheita nas características físicas, composição química do grão e qualidade do café.

Pesquisa Agropecuária Brasileira, Brasília, v.29, p.299308, 1994.

MALAVOLTA, E.; VITTI, G.C.; OLIVEIRA, S.A. Avaliação do estado nutricional das plantas: princípios e aplicações. 2.ed. Piracicaba: Potafos, 1997. 319p.

MARTINS, D.R.; CAMARGO, O.A. de; BATAGLIA, O.C. Qualidade do grão e da bebida em cafeeiros tratados com lodo de esgoto. Bragantia, Campinas, v.64, n.1, p.115-126, 2005.

MAZZAFERA, P.; GONÇALVES, K.V.; SHIMIZU, M.M. Extração e dosagem da atividade da polifenoloxidase do café. Scientia Agrícola, Piracicaba, v.59, n.4, p.695-700, out./dez. 2002.

PARTELLI, F.L.; VIEIRA, H.D.; MONNERAT, P.H.; VIANA, A.P. Comparação de dois métodos DRIS para o diagnóstico de deficiências nutricionais do cafeeiro.
Pesquisa Agropecuária Brasileira, Brasília, v.42, n.2, p.301-306, 2006.

PONTING, J.D.; JOSLYNG, M.A. Ascorbic acid oxidation and browning in apple tissue extracts. Achives of Biochemistry, New York, v.19, p.47-63, 1948.

REIS JÚNIOR, R.A.; MONNERAT, P.H. Validação de normas DRIS para a cultura da cana-de-açúcar. Pesquisa Agropecuária Brasileira, Brasília, v.38, n.3, p.379-385, 2003.

SANTOS, M.A.; CHALFOUN, S.M.; PIMENTA, C.J. Influência o processamento por via úmida e tipos de secagem sobre a composição, físico química e química do café (Coffea arabica L). Ciência e Agrotecnologia, Lavras, v.33, n.1, p.213-218, jan./fev. 2009.

SILVA, E. B.; NOGUEIRA, F.D.; GUIMARÃES, P.T.G. Uso de DRIS na avaliação do estado nutricional do cafeeiro em resposta à adubação potássica. Revista Brasileira de Ciência do Solo, Viçosa, v.27, n.2, p.247-255, mar./abr. 2003.

SILVA, E.B.; NOGUEIRA, F.D.; GUIMARÃES, P.T.G. Qualidade dos grãos de café em função de doses de potássio. Acta Scientiarum, Maringá, v.24, n.5, p.12911297, 2002.

SILVA, M.C. da; CASTRO, H.A.O.; FARNEZI, M.M.M.; PINTO, N.A.V.D.; SILVA, E.B. Caracterização química e sensorial de cafés da chapada de minas, visando determinar a qualidade final do café de alguns municípios produtores. Ciência e Agrotecnologia, Lavras, v.33, p.1782-1787, 2009. Edição especial.

SINGLETON, V.L. The total phenolic content of grapes berries during the maturation of several varieties.

American Journal Enology Viticulture, Davis, v.17, p.126-134, 1966. 